
\title{
Journal of Management
}

\section{Bayesian Probability and Statistics in Management Research : A New Horizon}

Michael J. Zyphur and Frederick L. Oswald

Journal of Management 2013 39: 5 originally published online 17 October 2012

DOI: 10.1177/0149206312463183

The online version of this article can be found at:

http://jom.sagepub.com/content/39/1/5

\section{Published by:}

(3)SAGE

http://www.sagepublications.com

On behalf of:

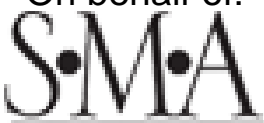

SOUTHERN

MANAGEMENT

Southern Management Association

Additional services and information for Journal of Management can be found at:

Email Alerts: http:/jom.sagepub.com/cgi/alerts

Subscriptions: http://jom.sagepub.com/subscriptions

Reprints: http://www.sagepub.com/journalsReprints.nav

Permissions: http://www.sagepub.com/journalsPermissions.nav

>> Version of Record - Nov 27, 2012

OnlineFirst Version of Record - Oct 17, 2012

What is This? 
Journal of Management

Vol. 39 No. 1, January 2013 5-13

DOI: $10.1177 / 0149206312463183$

(C) The Author(s) 2013

Reprints and permission: http://www.

sagepub.com/journalsPermissions.nav

Call for Papers

\title{
Bayesian Probability and Statistics in Management Research: A New Horizon
}

\author{
Guest Editors \\ Michael J. Zyphur, University of Melbourne \\ Frederick L. Oswald, Rice University
}

\begin{abstract}
Special Issue Purpose
This special issue is focused on how a Bayesian approach to estimation, inference, and reasoning in organizational research might supplement—and in some cases supplant—-traditional frequentist approaches. Bayesian methods are well suited to address the increasingly complex phenomena and problems faced by 21 st-century researchers and organizations, where very complex data abound and the validity of knowledge and methods are often seen as contextually driven and constructed. Traditional modeling techniques and a frequentist view of probability and method are challenged by this new reality.
\end{abstract}

Keywords: Bayes, Bayesian, probability, statistics, research methods, philosophy of science, frequentist

\section{Background}

Since probability in its modern form emerged in the 1600s, it has had two faces (Hacking, 2006). They are often called frequentist and Bayesian (Fienberg, 2006). There is a long history of debate among philosophers, scientists, and statisticians over which is better suited for estimation and inference (Efron, 2005, 2010; Gigerenzer, 1987, 1993; Good, 1989; Little, 2006). However, history shows that both types of probability used to exist harmoniously to solve problems. For example, Gauss and Laplace used the central limit theorem (frequentist) and posterior probabilities (Bayesian) to justify aggregating observations with the method of least squares (Stigler, 1986). Unfortunately, beginning in the mid-1800s, the distinction 
between frequentist and Bayesian probability became divisive (Daston, 1994, 1995), with continued wrangling in the 20th century (Howie, 2002) as Fisher and other statisticians popularized frequentist methods, such as null hypothesis significance testing (NHST; Aldrich, 2008; Danziger, 1994; Gigerenzer, Swijtink, Porter, Daston, Beatty, \& Krüger, 1989; MacKenzie, 1981; Zabell, 1989). Organization science researchers followed the path of most other quantitative social sciences and adopted the frequentist approach to probability in the latter half of the 20th century. The adoption was wholesale, so that today quantitative research in the organization sciences relies on $p$ values, maximum likelihood (ML) estimation, and other frequentist statistical tools. Although frequentist methods are capable of answering certain types of questions, a "Bayesian revolution" is currently under way in statistics and elsewhere. Indeed, Bayesian analysis finds widespread use in a sweeping array of scientific disciplines, such as physics, chemistry, biology, computer science, genetics, bioinformatics, atmospheric science, and economics. To date, however, the organization sciences have hardly participated in or evaluated the benefit of the Bayesian revolution.

\section{Research Tracks}

With this history in mind, the special issue is open to three distinct, yet related, tracks that constellate around Bayesian estimation, inference, and reasoning in organizational research. To assist contributors, we provide some thoughts and ideas within each track, but the call for papers is certainly not limited to only these ideas.

\section{Theoretical or empirical work describing Bayesian estimation and inference to address and answer organizational/management research questions.}

Today, statisticians often use both Bayesian and frequentist techniques for estimation and inference (Efron, 2005, 2010; Little, 2006), and there are many situations where both techniques are useful and can inform one another (see Bayarri \& Berger, 2004; Berger, 2003; Berger, Boukai, \& Wang, 1997; Berger, Brown, \& Wolpert, 1994; Selke, Bayarri, \& Berger, 2001). Contrasting or combining frequentist and Bayesian estimation and inference can provide a useful conceptual understanding of the plurality of probability in organizational research, and, practically speaking, it leads to developing (and learning how to develop and be open to) a more versatile statistical toolbox for organizational researchers.

Bayesian methods allow answering questions about parameters and models directly: "What is the probability of a set of research-relevant parameters, hypotheses, or statistical models given the observed data?" Frequentist estimation and inference with NHST answer the "inverse" type of question: "What is the probability of the data given what are often research-irrelevant parameters specified by the null hypothesis?" (Berger \& Selke, 1987; Kruschke, 2010a, 2010b, 2011). In other words, Bayesian techniques condition on data that are viewed as fixed to determine a distribution of possible parameters; frequentist techniques condition on parameters that are viewed as fixed to determine a distribution of possible data that are never empirically observed (Wagenmakers, Lee, Lodewyckx, \& Iverson, 2008). Organizational researchers should understand the research conditions under which Bayesian and frequentist questions and answers are more (and less) useful. 
Bayesian estimation and inference have many advantages (Kadane, 1995): rich diagnostic information about parameters and models; controlling for multiple comparisons as a function of the data; handling low-frequency, unbalanced, missing data; and exploration of prior assumptions about model parameters. Also, instead of focusing on Type I and Type II errors, Bayesian thinking places the focus on whether or not parameters and models are sensible for a set of data (e.g., credibility intervals instead of confidence intervals), rather than whether a specific "correct" model has been specified or a null model is rejected (Howson \& Urbach, 2006). This is related to the ability to conduct interim analyses or types of "sequential analysis" (see Howson \& Urbach, 2006), which in some research contexts can literally save lives (e.g., Cheng \& Madigan, 2010). Organizational researchers should understand how all of these factors could influence the decision between frequentist and Bayesian methods.

Organizational and management researchers will benefit from greater exposure to Bayesian methods and software (e.g., Mplus, R packages, WinBUGS, JAGS, Analytica), the practical issues faced when taking a Bayesian approach (e.g., model identification, the stability of parameter estimates, choosing priors in good faith), and strategies and materials for reporting and publishing Bayesian research (e.g., useful templates for tables and graphs). Zyphur and Oswald (2012) provide an introduction to these issues, but more work is needed for explaining the statistical methods and software that are available, along with relevant and useful examples. In addition to a tutorial of the logistics, practicalities, and examples of conducting Bayesian analysis, the special issue is also interested in papers that address when or why a particular Bayesian technique or logical approach might work best in a certain organizational research context. Such papers should address questions pertaining to data, models, audiences, contexts in which results will be communicated and used, and other key factors that determine the validity and legitimacy of any statistical methods for estimation and inference. For example, how Bayesian methods could be used for graduate education or for bridging the academic-practitioner divide would be of interest.

\section{Empirical management research that features specific types of Bayesian logic and methods to estimate models that are impossible, difficult, or otherwise inhibited by a frequentist paradigm.}

Bayesian estimation allows for flexible modeling in situations where a traditional frequentist approach is impossible (Efron, 2010). For example, structural equation models (SEM) with many latent and categorical observed variables require high-dimensional integration of a parameter space that cannot be conducted by closed-form ML methods. This problem is overcome with Bayesian methods that take advantage of Markov chain Monte Carlo estimation (Asparouhov \& Muthén, 2010; Lee, 2007; Muthén, 2010; Muthén \& Asparouhov, in press). Bayesian methods will become increasingly critical for modeling the vast multilevel, multisource, and longitudinal data that are increasingly available to organization researchers.

Furthermore, because Bayesian estimation incorporates existing data and prior information (probabilities), researchers can estimate parameters that would be impossible with ML methods (Garrett \& Zeger, 2000). For example, underidentified models in SEM-with saturated cross-loadings and residual correlations - can be estimated with Bayesian methods (Muthén \& Asparouhov, in press; Zyphur \& Oswald, 2012). Other very complex models that 
cannot be estimated with frequentist statistical tools can be gracefully accommodated using a Bayesian approach.

Another advantage of Bayesian methods is in dealing with information provided by small samples, where statistical power issues make it nearly impossible to support frequentist hypotheses with $p$ values, even when researchers find exactly what they have predicted (Howson \& Urbach, 2006). Bayesian estimation allows incorporating prior empirical findings and theory into model estimation in a scientifically principled manner (Zyphur \& Oswald, 2012). Bayesian methods are useful for investigating the rare but extremely important events that define organizational life in a quantitative manner that builds on past empirical findings and theory.

3. Work based in the history and philosophy of science (HPS), the sociology of scientific knowledge (SSK), and/or the field of science, technology, and society (STS) - focusing on knowledge creation with Bayesian methods in organizational research.

Researchers perform induction every time they make inferences from the particular (e.g., a sample) to the general (e.g., a population and/or other contexts), yet Bayesian and frequentists tend to do this in different ways. Although frequentists may focus on theory/ model falsification (e.g., Fisher, 1935a, 1935b; Popper, 1959/2002), Bayesians tend to focus on theory/model confirmation (e.g., Howson \& Urbach, 2006; see Lange, 2011; Press, 2010: 217-232). Often, organizational researchers do not rely on statistics and probability for induction or generalization in a logically consistent manner. As elsewhere (see Kadane, 1999), they rely on a hybrid of Fisher's (1935a), Neyman and Pearson's (1933), and Neyman's (1937) logic with $p$ values, confidence intervals, and Type I and Type II error rates that result in conceptualizations of scientific rigor and generalizability that are good for certain purposes but also limit methods of inquiry, scientific reasoning, and reflexivity (Gigerenzer, 1993, 2004; Gigerenzer et al., 1989; Gigerenzer \& Murray, 1987: 1-28). Discussions from philosophy of science on probability's role in induction abound (e.g., Cox \& Mayo, 2009; Mayo \& Cox, 2009; Zabell, 2011), and from these discussions it is clear that both Bayesians and frequentists operate with assumptions that are impossible to fulfill (see Hájek, 2009; Howson \& Urbach, 2006; Senn, 2011). Organizational researchers would benefit from understanding how incorporating or shifting toward Bayesian methods will lead to different assumptions, and how Bayesian probability and methods can facilitate a capable shift when moving research findings from specific contexts to other domains-perhaps through practice (e.g., Verran, 2001). For guidance on developing "evidence for use," a welldeveloped framework is by Cartwright (2006, 2007, 2010).

As Ellis (1842: 1) notes, "The theory of probabilities is at once a metaphysical and mathematical science." The philosophies underlying Bayesian and frequentist probability paradigms lack cohesion because they define different realities (see Galavotti, 2005). So-called frequentist probability is sometimes confused with stable propensities of chance setups (e.g., Peirce, 1923/2010; Popper, 1959/2002) but usually means hypothetical longrunning frequencies (e.g., Ellis, 1842, 1854; Neyman, 1937; Venn, 1866/2006; von Mises, 1957; see Maher, 2010). Alternatively, "Bayesian" probability can be a degree of rational knowledge or inductive, logical, or evidential support for a proposition or state of affairs 
(e.g., Bayes, 1763; Carnap, 1950; Jaynes, 2003; Jeffreys, 1939/1998; Keynes, 1921/2008; Laplace, 1774/1986; Shannon, 1948), or it can be a degree of belief in a proposition or state of affairs (e.g., De Finetti, 1931/1989; Jeffrey, 2004; Ramsey, 1926/1990; Savage, 1954; see Galavotti, 2011). We are interested in how the ontologies and epistemologies of each can affect the way management researchers conceptualize organizations and their members, as well as intervene in existing organizational practices and enact different organizational realities (e.g., Hacking, 1983; Latour, 2004; Law, 2004; Shapin \& Schaffer, 1985).

Statistics and probability involve social practices that structure and legitimize ways of measuring, understanding, and interacting (Gephart, 2006) — statistics and probability are necessary for the modern world to operate as it currently does (Hacking, 1990; Howie, 2002; Porter, 1986). How statistics and probability bring with them a "style of reasoning" (Hacking, 1992, 2002: 159-199) and practices that define organizations and organization science is of interest. An SSK/STS lens would be helpful to understand how statistics and probability work in both management research and organizations, and how pluralizing probability could usefully change organizational research.

To these ends we encourage (although do not require) cross-disciplinary perspectives and collaborations among management researchers, statisticians, and probability theorists, as well as scholars from HPS and SSK/STS.

As is the case for all contributions to Journal of Management, papers should offer conceptual and/or empirical insights that substantially advance the organizational literature.

\section{A Caveat}

Given the difficult history of probability and statistics (see Daston, 1995; Howie, 2002), we will not entertain papers whose sole purpose is to lambaste null-hypothesis significance testing or frequentist probability more generally. Instead, the special issue is more concerned with when and in which contexts adopting Bayesian techniques and logic will provide theoretical and practical benefits for organizational researchers as a complement or alternative to frequentist methods. The special issue also welcomes papers that connect with the many other disciplines developing and using Bayesian methods, whether that is through multidisciplinary collaboration, by drawing analogies with the Bayesian methods employed in other disciplines, or through other means.

\section{Further Reading}

For introductions to Bayesian estimation and inference, see Muthén (2010), Muthén and Asparouhov (in press), and Zyphur and Oswald (2012), who in turn provide references to more technical work (e.g., Gelman, Carlin, Stern, \& Rubin, 2003; Gill, 2007). From a philosophy of science perspective, the edited volume by Gabbay, Hartmann, and Woods (2011) and Bandyopadhyay and Forster (2011) provide comprehensive introductions; Howson and Urbach (2006) give thorough pro-Bayesian arguments; Hacking (2001) provides a very accessible overview of probability and inductive logic; Maher (2010) provides an online, and opinionated, perspective; and Galavotti's $(2005,2011)$ work is quite 
developmental. From a historical and sociological perspective, we recommend the work of Hacking (1990, 1992, 2002, 2006) as well as pieces by Danziger (1994), Daston (1995), Gigerenzer and colleagues (1989), Howie (2002), MacKenzie (1981), Porter (1986), and Stigler (1986) and two edited volumes by Krüger, Daston, and Heidelberger (1987) and Krüger, Gigerenzer, and Morgan (1990).

\section{Deadlines and Submission Instructions}

Please submit your papers online via the Journal of Management manuscript submission website (http://mc.manuscriptcentral.com/jom), and please indicate that the work is intended for this special issue. Papers may be submitted any time, up until December 15, 2013. Papers will be reviewed immediately upon submission. JOM averages a 40-day decision window. Papers that are accepted for publication will be immediately produced as discoverable in press papers and distributed ahead of print. No submissions will be reviewed after December 15, 2013. Please be sure to follow the Submission Guidelines (http://www.sagepub.com/journalsProdDesc.nav?crossRegion=nAmerica\&prodId=Journal20 1724\&crossRegion=antiPod\#tabview=manuscriptSubmission) as well as the JOM Style Guide (http://www.sagepub.com/upm-data/46742_JOM_Style_Guide_Revised_2011.pdf). Papers

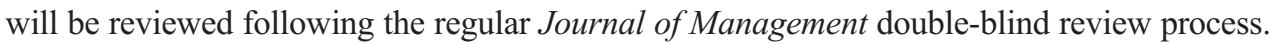

\section{More Information}

Please contact the Special Issue Editors for additional information, for feedback on a proposed topic or study, and to volunteer to review or recommend reviewers for this special issue:

Mike Zyphur, University of Melbourne, mzyphur@unimelb.edu.au

Fred Oswald, Rice University, foswald@rice.edu

\section{References}

Aldrich, J. 2008. R. A. Fisher on Bayes and Bayes' theorem. Bayesian Analysis, 3: 161-170.

Asparouhov, T., \& Muthén, B. 2010. Bayesian analysis of latent variable models using Mplus. Unpublished manuscript. www.statmodel.com/download/BayesAdvantages 18.pdf.

Bandyopadhyay, P. S., \& Forster, M. R. 2011. Handbook of the philosophy of science: Philosophy of statistics, vol. 7. Oxford, UK: Elsevier.

Bayarri, M. J., \& Berger, J. O. 2004. The interplay of Bayesian and frequentist analysis. Statistical Science, 19: 58-80.

Bayes, T. P. 1763. An essay towards solving a problem in the doctrine of chances. Philosophical Transactions of the Royal Society of London, 53: 370-418.

Berger, J. 2003. Could Fisher, Jeffreys, and Neyman have agreed on testing? Statistical Science, 18: 1-32.

Berger, J. O., Boukai, B., \& Wang, Y. 1997. Unified frequentist and Bayesian testing of a precise hypothesis. Statistical Science, 12: 133-160.

Berger, J. O., Brown, L. D., \& Wolpert, R. L. 1994. A unified conditional frequentist and Bayesian test for fixed and sequential simple hypothesis testing. Annals of Statistics, 22: 1787-1807.

Berger, J. O., \& Selke, T. 1987. Testing a point null hypothesis: The irreconcilability of $p$ values and evidence. Journal of the American Statistical Association, 82: 112-122. 
Carnap, R. 1950. Logical Foundations of Probability. Chicago: University of Chicago Press.

Cartwright, N. D. 2006. Well-ordered science: Evidence for use. Philosophy of Science, 73: 981-990.

Cartwright, N. D. 2007. Hunting causes and using them. Cambridge, UK: Cambridge University Press.

Cartwright, N. D. 2010. Predicting "it will work for us": (Way) beyond statistics. In P. M. Illari, F. Russo, \& J. Williamson (Eds.), Causality in the sciences: 750-768. Oxford, UK: Oxford University Press.

Cheng, J., \& Madigan, D. 2010. Bayesian approaches to aspects of the Vioxx trials: Non-ignorable dropout and sequential meta-analysis. In A. O'Hagan \& M. West (Eds.), The Oxford handbook of applied Bayesian analysis: 51-68. Oxford, UK: Oxford University Press.

Cox, D., \& Mayo, D. G. 2009. Objectivity and conditionality in frequentist inference. In D. G. Mayo \& A. Spanos (Eds.), Error and inference: Recent exchanges on experimental reasoning, reliability, and the objectivity and rationality of science: 276-304. Cambridge, UK: Cambridge University Press.

Danziger, K. 1994. Constructing the subject: Historical origins of psychological research. Cambridge, UK: Cambridge University Press.

Daston, L. 1994. How probabilities came to be subjective and objective. Historia Mathematica, 21: 330-344.

Daston, L. 1995. Classical probability in the Enlightenment. Princeton, NJ: Princeton University Press.

De Finetti, B. 1931/1989. Probabilism. Erkenntnis (M. C. Di Maio, M. C. Galavotti, \& R. C. Jeffrey, Trans.), 31: $169-223$.

Efron, B. 2005. Bayesians, frequentists, and statisticians. Journal of the American Statistical Association, 100: 1-5.

Efron, B. 2010. Large-scale inference: Empirical Bayes methods for estimation, testing, and prediction. Cambridge, UK: Cambridge University Press.

Ellis, R. L. 1842. On the foundations of the theory of probabilities. Transactions of the Cambridge Philosophical Society, 8: 1-6. http://www.biodiversitylibrary.org/item/49441\#page/17/mode/1up.

Ellis, R. L. 1854. Remarks on the fundamental principle of the theory of probabilities. Transactions of the Cambridge Philosophical Society, 9: 605-607. http://www.biodiversitylibrary.org/item/19878\#page/701/ mode/1up.

Fienberg, S. E. 2006. When did Bayesian inference become "Bayesian"? Bayesian Analysis, 1: 1-40.

Fisher, R. A. 1935a. Design of experiments. Edinburgh, UK: Oliver \& Boyd.

Fisher, R. A. 1935b. The logic of inductive inference. Journal of the Royal Statistical Society, 98: 39-54.

Gabbay, D. M., Hartmann, S., \& Woods, J. 2011. Handbook of the history of logic: Inductive logic, vol. 10. Oxford, UK: Elsevier.

Galavotti, M. C. 2005. Philosophical introduction to probability. Palo Alto, CA: CSLI.

Galavotti, M. C. 2011. The modern epistemic interpretations of probability: Logicism and subjectivism. In D. M. Gabbay, S. Hartmann, \& J. Woods (Eds.), Handbook of the history of logic: Inductive logic, vol. 10: 153-203. Oxford, UK: Elsevier.

Garrett, E. S., \& Zeger, S. L. 2000. Latent class model diagnosis. Biometrics, 56: 1055-1067.

Gelman, A., Carlin, J. B., Stern, H. S., \& Rubin, D. B. 2003. Bayesian data analysis (2nd ed.). Boca Raton, FL: Chapman \& Hall.

Gephart, R. P. 2006. Ethnostatistics and organizational research methods. Organizational Research Methods, 9: 417-431.

Gigerenzer, G. 1987. Probabilistic thinking and the fight against subjectivity. In L. Krüger, G. Gigerenzer, \& M. S. Morgan (Eds.), The probabilistic revolution, vol. 2: 11-33. Cambridge, MA: MIT Press.

Gigerenzer, G. 1993. The superego, the ego, and the id in statistical reasoning. In G. Keren \& C. Lewis (Eds.), $A$ handbook for data analysis in the behavioral sciences: Methodological issues: 311-339. Hillsdale, NJ: Lawrence Erlbaum.

Gigerenzer, G. 2004. Mindless statistics. Journal of Socio-Economics, 33: 587-606.

Gigerenzer, G., \& Murray, D. J. 1987. Cognition as intuitive statistics. New York: Psychology Press.

Gigerenzer, G., Swijtink, Z., Porter, T., Daston, L., Beatty, J., \& Krüger, L. 1989. The empire of chance: How probability changed science and everyday life. Cambridge, UK: Cambridge University Press.

Gill, J. 2007. Bayesian methods: A social and behavioral sciences approach (2nd ed.). Boca Raton, FL: Chapman \& Hall.

Good, I. J. 1989. Good thinking: The foundations of probability and its applications. Mineola, NY: Dover.

Hacking, I. 1983. Representing and intervening: Introductory topics in the philosophy of natural science. 
Cambridge, UK: Cambridge University Press.

Hacking, I. 1990. The taming of chance. Cambridge, UK: Cambridge University Press.

Hacking, I. 1992. Statistical language, statistical truth and statistical reason: The self-authentication of a style of scientific reasoning. In E. McMullin (Ed.), The social dimensions of science, vol. 3: 130-157. Notre Dame, IN: University of Notre Dame Press.

Hacking, I. 2001. An introduction to probability and inductive logic. Cambridge, UK: Cambridge University Press. Hacking, I. 2002. Historical ontology. Cambridge, MA: Harvard University Press.

Hacking, I. 2006. The emergence of probability: A philosophical study of early ideas about probability, induction and statistical inference. Cambridge, UK: Cambridge University Press.

Hájek, A. 2009. Fifteen arguments against hypothetical frequentism. Erkenntnis, 70: 211-235.

Howie, D. 2002. Interpreting probability: Controversies and developments in the early twentieth century. Oxford, UK: Oxford University Press.

Howson, C., \& Urbach, P. 2006. Scientific reasoning: The Bayesian approach (3rd ed.). Peru, IL: Open Court.

Jaynes, E. T. 2003. Probability theory: The logic of science. Cambridge, UK: Cambridge University Press.

Jeffrey, R. 2004. Subjective probability: The real thing. Cambridge, UK: Cambridge University Press.

Jeffreys, H. 1939/1998. Theory of probability (3rd ed.). Oxford, UK: Clarendon.

Kadane, J. B. 1995. Prime time for Bayes. Controlled Clinical Trials, 16: 313-318.

Kadane, J. B. 1999. The insignificance of null hypothesis significance testing. Political Research Quarterly, 52: 647-674.

Keynes, J. M. 1921/2008. A treatise on probability. Seaside, OR: Rough Draft Printing.

Krüger, L., Daston, L. J., \& Heidelberger, M. 1987. The probabilistic revolution: Ideas in history, vol. 1. Cambridge, MA: MIT Press.

Krüger, L., Gigerenzer, G., \& Morgan, M. S. (1990). The probabilistic revolution: Ideas in the sciences, vol. 2. Cambridge, MA: MIT Press.

Kruschke, J. K. 2010a. Bayesian data analysis. Wiley Interdisciplinary Reviews: Cognitive Science, 1: 658-676.

Kruschke, J. K. 2010b. What to believe: Bayesian methods for data analysis. Trends in Cognitive Sciences, 14 : 293-300.

Kruschke, J. K. 2011. Bayesian assessment of null values via parameter estimation and model comparison. Perspectives on Psychological Science, 6: 299-312.

Lange, M. 2011. Hume and the problem of induction. In D. M. Gabbay, S. Hartmann, \& J. Woods (Eds.), Handbook of the history of logic: Inductive logic, vol. 10: 43-91. Oxford, UK: Elsevier.

Laplace, P. S. 1774/1986. Memoir on the probability of the causes of events (S. M. Stigler, Trans.). Statistical Science, 3: 364-378.

Latour, B. 2004. Why has critique run out of steam? From matters of fact to matters of concern. Critical Inquiry, 30: $225-248$.

Law, J. 2004. After method: Mess in social science research. London: Routledge.

Lee, S.-Y. 2007. Structural equation modeling: A Bayesian perspective. Chichester, UK: Wiley.

Little, R. J. 2006. Calibrated Bayes: A Bayes/frequentist roadmap. American Statistician, 60: 213-223.

MacKenzie, D. 1981. Statistics in Britain, 1865-1930: The social construction of scientific knowledge. Edinburgh, UK: Edinburgh University Press.

Maher, P. 2010. What is probability? Unpublished manuscript. http://patrick.maher1.net/preprints/pop.pdf.

Mayo, D. G., \& Cox, D. 2009. Frequentist statistics as a theory of inductive inference. In D. G. Mayo \& A. Spanos (Eds.), Error and inference: Recent exchanges on experimental reasoning, reliability, and the objectivity and rationality of science: 247-275. Cambridge, UK: Cambridge University Press.

Muthén, B. 2010. Bayesian analysis in Mplus: A brief introduction. Unpublished manuscript. www.statmodel.com/ download/IntroBayesVersion\%203.pdf.

Muthén, B., \& Asparouhov, T. In press. Bayesian SEM: A more flexible representation of substantive theory. Psychological Methods.

Neyman, J. 1937. Outline of a theory of statistical estimation based on the classical theory of probability. Philosophical Transactions of the Royal Society of London, Series A, 236: 333-380.

Neyman, J., \& Pearson, E. 1933. On the problem of the most efficient tests of statistical hypotheses. Philosophical Transactions of the Royal Society of London, Series A, 231: 289-337.

Peirce, C. S. 1923/2010. Chance, love, and logic: Philosophical essays (with a supplemental essay by John Dewey). 
Charleston, SC: Nabu Press.

Popper, K. 1959/2002. The logic of scientific discovery. New York: Routledge.

Porter, T. M. 1986. The rise of statistical thinking, 1820-1900. Princeton, NJ: Princeton University Press.

Press, S. J. 2010. Subjective and objective Bayesian statistics: Principles, models, and applications (2nd ed.). New York: John Wiley.

Ramsey, F. P. 1926/1990. Truth and probability. In D. H. Mellor (Ed.), Philosophical papers: 52-94. Cambridge, UK: Cambridge University Press.

Savage, L. J. 1954. Foundations of statistics. New York: John Wiley.

Selke, T., Bayarri, M. J., \& Berger, J. O. 2001. Calibration of $p$ values for testing precise null hypotheses. American Statistician, 55: 62-71.

Senn, S. 2011. You may believe you are a Bayesian but you are probably wrong. Rationality, Markets, and Morals, 2: 48-66.

Shannon, C. E. 1948. A mathematical theory of communication. Bell System Technical Journal, 27: 379-423.

Shapin, S., \& Schaffer, S. 1985. Leviathan and the air-pump. Princeton, NJ: Princeton University Press.

Stigler, S. M. 1986. The history of statistics: The measurement of uncertainty before 1900. Cambridge, MA: Harvard University Press.

Venn, J. 1866/2006. The logic of chance. Mineola, NY: Dover.

Verran, H. 2001. Science in an African logic. Chicago: University of Chicago Press.

von Mises, R. 1957. Probability, statistics, and truth. Mineola, NY: Dover.

Wagenmakers, E.-J., Lee, M., Lodewyckx, T., \& Iverson, G. 2008. Bayesian versus frequentist inference. In H. Hoijtink, I. Klugkist, \& P. A. Boelen (Eds.), Bayesian evaluation of informative hypotheses: 181-207. New York: Springer.

Zabell, S. 1989. R. A. Fisher on the history of inverse probability. Statistical Science, 4: 247-263.

Zabell, S. 2011. Carnap and the logic of induction. In D. M. Gabbay, S. Hartmann, \& J. Woods (Eds.), Handbook of the history of logic: Inductive logic, vol. 10: 265-309. Oxford, UK: Elsevier.

Zyphur, M. J., \& Oswald, F. L. 2012. Bayesian estimation and inference: A user's guide. Unpublished manuscript. 